http://jmscr.igmpublication.org/home/ ISSN (e)-2347-176x ISSN (p) 2455-0450 crossref DOI: https://dx.doi.org/10.18535/jmscr/v8i11.07

\author{
Journal Of Medical Science And Clinical Research \\ IGM Publication \\ An Official Publication of IGM Publication
}

\title{
Early Enteral Feeding in Gastrointestinal Surgery
}

Authors

\section{Dr R.Logesh Kumar ${ }^{1}$, Dr N.Junior Sundresh ${ }^{2}$, Dr D.Gopikrishna ${ }^{3}$, \\ Dr P.Vigneshwaran ${ }^{4}$, Dr A.P.S.Gurupraveen ${ }^{5}$}

${ }^{1,4,5}$ Post Graduate, Dept of General Surgery, Rajah Muthiah Medical College and Hospital, Annamalai

Nagar, Chidambaram, India, 608002

${ }^{2}$ Professor, Dept of General Surgery, Rajah Muthiah Medical College and Hospital, Annamalai Nagar, Chidambaram, India, 608002

${ }^{3}$ Associate Professor, Dept of General Surgery, Rajah Muthiah Medical College and Hospital, Annamalai

Nagar, Chidambaram, India, 608002

*Corresponding Author

Dr D.Gopikrishna

Associate Professor, Dept of General Surgery, Rajah Muthiah Medical College and Hospital, Annamalai

Nagar, Chidambaram, India, 608002

Abstract
Traditionally, after abdominal surgery, the passage of flatus, or bowel movement was the clinical
evidence for starting an oral diet. Studies were undertaken to evaluate whether different abdominal
surgeries could benefit from early feeding. So a study was carried out prospectively to analyze the
benefits and clinical outcome of 46 patients who received early enteral feeding following GI surgery. A
nasogastric feeding tube placed by the surgeon beyond the pylorus through which continuous infusion of
peptide-based diet was administered. NG feeds were started 4 to 6 hours following surgery and increased
at a rate of 50 mL/hour on the postoperative day - Three. Feeds were given either distal or proximal to
their anastomosis. 46 patients met the exclusion and inclusion criteria were included in the study.
Enteral feeding was well tolerated by the patients with less side effects, in some case nausea and
vomiting is present which is being the most frequent. 48 hours after surgery oral feeding was started.
There is faster recovery of bowel function due to early enteral feeding. Enteral feeding also leads to a
decreased hospital stay.
Keywords: feeding tube, elemental diet, gastrointestinal surgery, enteral nutrition.

\section{Introduction}

Early enteral feeding is superior than total parenteral nutrition (TPN) for various reasons such as preserves gut immunity, motility, TPN catheter associated infections, route for access is very easy. Between $30 \%$ and $50 \%$ of hospitalized patients are malnourished because of lack of good nutritious feed. Lack of feeding result in diminished wound healing, predisposition to infection, and increased postoperative morbidity. Although most healthy individuals can tolerate up to 7 days of starvation (with adequate glucose and fluid replacement), those subjected to major trauma, and the physiologic stress of surgery, 
sepsis, or cancer-related. cachexia require nutritional intervention much sooner. ${ }^{1-2}$ In this study we evaluated the benefits and role of early enteral feeding in gastrointestinal (GI) surgery patients.

\section{Materials and Methods}

A study was carried out in a prospective manner in patients following GI surgery with intestinal anastomoses, from July 2018 to August 2020 in Rajah Muthiah Medical College and Hospital, Chidambaram. Patients without purulent peritonitis, with pathology of non-traumatic etiology and who maintained at least 1.5 metre of small bowel were included. After the surgery the operating surgeon inserted a $10-\mathrm{Fr}$ nasointestinal feeding tube distal to the pylorus. After 4 to 6 hours of surgery, continuous infusion of an elemental peptide-based diet at a rate of 20 $\mathrm{ml} /$ hour for the first 24 hours, then increased to 40 $\mathrm{ml} / \mathrm{h}$ during the second day, and $60 \mathrm{ml} / \mathrm{h}$ during the third day and following days as needed for a total volume of $1500 \mathrm{ml} /$ day. If audible bowel sounds were present oral feeding was started and there was no evidence of nausea, vomiting or abdominal distention. The patients were given intravenous fluids upto $2500 \mathrm{ml} / \mathrm{d}$. Additional losses through tubes and drains were replaced as needed.

The antibiotics were given to all the patients prophylactically and therapeutically. A written informed consent form was obtained. The parameters studied were nausea, vomiting, abdominal distention, diarrhea and complications like intra-abdominal abscess, wound infection, intestinal suture leak, peritonitis and pneumonia. Also day of nasointestinal feeding tube removal, length of hospital stay, and mortality were studied.

\section{Results}

Forty-six patients were included in the study. Displacement of the feeding tube back into the stomach in 6 patients, and $24 \mathrm{~h}$ infusion given to 3 patients after the postoperative period. 46 patients formed the study group. Enteral feeding was started 4 to 6 hours after surgery. The average volume of diet given per patient was $500 \mathrm{ml}$, and the highest consumption was $6500 \mathrm{ml}$ in a patient following pancreaticoduodenectomy who presented with a high-output pancreatic fistula (660 $\mathrm{ml} / 24$ hour) on the postoperative day - 4 . On the third postoperative day nasogastric tube removed and oral feeding was started initially as clear liquids then progressed to a soft diet the same day if there was good tolerance. The average length of postoperative stay in hospital was 4 days.

Nine patients (19.56\%) developed nausea so infusion in feeding tube was stopped for 6 hours. Side effects are summarized in Table III. In one patient $(2.2 \%)$ it was necessary to stop EN permanently due to prolonged ileus, vomiting, and abdominal distention and a NG tube was placed for 3 days.

TABLE I.

\begin{tabular}{lc}
\hline \multicolumn{2}{c}{ PATIENT DIAGNOSES } \\
\hline Diagnoses & $n(\%)$ \\
\hline Peptic ulcer disease & $11 .(25)$ \\
Gastric carcinoma & $10(22)$ \\
Choledocholithiasis & $10(22)$ \\
Colon cancer & $2(4)$ \\
Pancreatic carcinoma & $2(4)$ \\
Chronicpancreatitis & $2(4)$ \\
Colostomy & $2(4)$ \\
Other pathologies & $7(15)$ \\
\hline
\end{tabular}

TABLE II.

SURGICAL PROCEDURES

\begin{tabular}{lc}
\hline Type of Procedure & $n(\%)$ \\
\hline Partial gastrectomy-Billroth 11 & $10(21.7)$ \\
Truncal vagotomy-pyloroplasty & $8(17.4)$ \\
Cholecystectomy-sphincterotomy and sphincteroplusty & $6(13)$ \\
Cholecystectomy-choledochoduoden ostomy & $4(8.7)$ \\
Colostomy/ileostomy closure & $4 t 8.7)$ \\
Hemicolectomy & $3(6.5)$ \\
Truncal vagotomy-gastrojejunostomy & $3(6.5)$ \\
Partial pancreatectomy & $2(4.3)$ \\
Choledochojejunostom y & $2(4.3)$ \\
Pancreaticoduodenectomy & $1(2.2)$ \\
Total gastrectomy & $1(2.2)$ \\
Other & $2(4.3)$ \\
\hline
\end{tabular}


There were postoperative complications in six patients. The most common complication was surgical site infection (4 patients, 8.7\%). Complications are listed in Table IV. Two patients presented with an intra-abdominal abscess. One patient who underwent gastrectomy presented later to the hospital, 30 days after surgery with a localized abscess. The other patient undergone a laparotomy procedure for the closure of an ileostomy and mucous fistula a jejunal diverticulum was found incidentally and removed during the same operation. The more distal ileostomy closure was intact.

Antibiotic therapy was used in all the patients (for more than 72 hours). Serum albumin levels obtained in 27 patients preoperatively $(3.05 \pm 0.89$ $\mathrm{g} / \mathrm{dL}$ ) indicated mild malnutrition.

\section{Discussion}

Early enteral feeding helps to maintain integrity of intestine. It can also decreases the risk of postoperative ileus., 3 -15 "Sagar et al. and others' ${ }^{16-19}$ have shown that intestinal absorptive capacity is not inhibited in the immediate postoperative period. ${ }^{4-6}$

TABLE III.

\begin{tabular}{lc}
\hline \multicolumn{2}{c}{ THE INCIDENCE OF SIDE EFFECTS } \\
\hline Side Effects & $n(\%)$ \\
\hline Nausea & $7(15)$ \\
Vomiting & $6(13)$ \\
Abdominal distention & $5(10)$ \\
Diarrhea & $1(2.2)$ \\
\hline
\end{tabular}

TABLE IV.

\begin{tabular}{ll}
\hline \multicolumn{2}{c}{ OBSERVED COMPLICATIONS } \\
\hline Morbidity & $n(\%)$ \\
\hline Wound infection & $4(8.7)$ \\
Intra-abdominal abscess & $2(4.4)$ \\
Suture leakage & $1(2.2)$ \\
Pancreatic fistula & $1(2.2)$ \\
\hline
\end{tabular}

The elemental diet is particularly useful in transition period while patient recovers bowel function post surgically. The use of NG tube for decompression is important to avoid abdominal distention during first few hours of post surgical period. Some authors considered diarrhoea as frequent complication in early enteral feeding may be due to the high osmotic load directly into the jejunum. $^{7-12}$

Radiologically we confirmed the position of nasogastric tube postoperatively. If there is a proximal displacement of the feeding tube, infusion was either stopped or not started. Nausea and vomiting were found to be the most frequent side effects. Aspiration pneumonia was the most lethal potential complication described in previous studies. In this present study, there is no aspiration pneumonia. $^{20}$

Intestinal suture leakage due to early administration of early enteral feeding has not been reported. Hypermetabolic response to injury starts immediately after surgery affecting the immune response and visceral protein mass creating the complications.

Some clinical studies shows that with early nutritional support this chain of events may be altered to some extent. Previous studies have shown a reduction in the incidence of septic events and a shorter hospital stay in patients who were receiving early enteral nutrition. Patients on EN developed less pneumonia and sepsis.

Observed wound infection in 4 patients $(8.7 \%)$, which is not significant. But In a old study of Moore et $\mathrm{al}^{21}{ }^{21}$ he conducted the study with 230 patients out of which 112 patients got TPN and 118 got early enteral feeding in post operative period which concludes reduction in septic complication in enteral group. In this study early EN improve bowel function earlier which lead to a shorter hospital stay.

Compared with intermittent infusion, continuous infusion is better tolerated, with a lower incidence of side effects such as diarrhea and abdominal pain and the possibility of achieving nutritional goals faster. 


\section{Summary}

Early enteral feeding is tolerated well by patients after elective Gastrointestinal surgery, with a low complications. The NG tube feeding is a cost effective and safe method for administering nutrition during the postoperative period. Early Enteral feeding favours faster return of bowel function after Gastrointestinal surgery, which leads to shorter hospital stay.

\section{References}

1. Grant JP, Curtas MS, Kelvin FM. Fluoroscopic placement of naso- jejunal feeding tubes with immediate feeding using a nonelemental diet. JPEN 1983; 7:299

2. Deitch EA, Winterton J, Li M, Berg R. The gut as a portal of entry for bacteremia. Ann Surg 1987; 205:681

3. Takala J, Havia T, Heinonen R, Renvall S. Immediate enteral feed- ing after abdominal surgery. Acta Chir Scand 1985; 151:143

4. Schroeder D, Gillanders L, Mahr K, Hill G. Effects of immediate postoperative enteral nutrition on body composition, muscle func- tion, and wound healing. JPEN 1991; 15:376

5. Moore FA, Moore EE, Jones TM, Me Croskey B, Peterson VM. TEN versus TPN following major abdominal traumareduced septic morbidity. J Trauma 1989; 29:916

6. McArdle AH, Palmason C, Morency Y, Brown RA. A rationale for enteral feeding as the preferable route for hyperalimentation. Surgery 1981; 90:616

7. Cappell MS, Scarpa PJ, Nadler S, Miller S. Complications of naso- enteral tubes. $\mathrm{J}$ Clin Gastroenterol 1992; 14:144

8. S. Cataldi-Betcher EL, Seltzer MH, Slocumb BA, Jones KW. Compli- cations occurring during enteral nutrition support: a prospective study. JPEN 1983; 7:546
9. Kudsk KA, Stone JM, Carpenter G. Effects of enteral and paren- teral feeding of malnourished rats on body composition. I Trauma 1982; 22:904

10. Kudsk KA, Croce MA, Fabian TC, et al. Enteral versus parenteral feeding. Ann Surg 1992; 215:503

11. Ruberg RL. Role of nutrition in wound healing. Surg Clin North Am 1984; 64:705

12. Ward MWN, Danzi M, Lewin MR, Rennie MJ, Clark CG. The effects of subclinical malnutrition and refeeding on the healing of experimental colonic anastomoses. $\mathrm{Br} \mathbf{J}$ Surg 1982; 69:308

13. Heberer M, Bodoky A, Iwatschenko P, Harder F. Indications for needle catheter jejunostomy in elective abdominal surgery. Am J Surg 1987; 153:545

14. Ryan I, Page CP. Babcock L. Early postoperative jejunal feeding of elemental diet in gastrointestinal surgery. Am Surg 1981;47:393

15. Dunn EL, Moore EE, Bohus RW. Immediate postoperative feeding following massive abdominal trauma the catheter jejunostomy. JPEN 1980: 4:393

16. Shoemaker CP, Wright HK. Rate of water and sodium absorption from the jejunum after abdominal surgery in man. Am J Surg 1970, 119:62

17. Fletcher JP, Little JM. A comparison of parenteral nutrition and early postoperative enteral feeding on the nitrogen balance after major surgery. Surgery 1986; 100:21

18. Moore EE, Todd NJ, Moore FA. Immediate postinjury enteral feeding: reducing gut bacterial translocation. Panam I Trauma 1989; 1:31

19. Sagar S, Harland P, Shields R. Early postoperative feeding with elemental diet. Br Med 1 1979; 1:293

20. Herrman ME, Liehr RM, Tanhoefner H. Enide C, Riecken EO. Subjective distress during continous enter $<$ il alimentation: 
superior- ity of silicone rubber to polyurethane. JPEN 1959; 13:281

21. Moore FA, Feliciano DV, Andrassy RJ. E<irly enteral feeding, com- pared with parenteral, reduces postoperative septic complications. Ann Surg 1992; 216:172. 